\title{
Natural Products Against the Zika Virus
}

\author{
Claudio C Cirne-Santos *, Caroline De S Barros and Izabel Christina N P Paixão \\ Department of Cellular and Molecular Biology, Universidade Federal Fluminense, Instituto de Biologia, 24020-141 Niterói, RJ, Brazil
}

*Corresponding author: Claudio C Cirne-Santos, Department of Universidade Federal Fluminense, Instituto De Biologia, 24020-141 Niterói, RJ, Brazil.

To Cite This Article: Claudio C Cirne-Santos, Natural Products Against the Zika Virus. 2020 - 7(3). AJBSR.MS.ID.001146.

DOI: 10.34297/AJBSR.2020.07.001146.

Received: 眥 February 11, 2020; Published: 眥 February 14, 2020

\section{Introduction}

The Zika virus belongs to the family Flaviviridae, which includes the well-known viruses associated with dengue, yellow fever, Nile fever in addition to the Japanese encephalitis virus. The discovery dates back to 1947 in Uganda, Africa, from an enzootic cycle between primates and wild Aedes aegypti, culminating in infections in humans [1]. In addition, sexual transmission of the infection may be a major concern in the spread of Zika [2]. It is said that Zika infection has been considered a serious threat to public health mainly due to the strong suspicions of its relationship with the development of microcephaly (affecting the development of fetuses of women infected during pregnancy and other congenital malformations)[3,4]. Other serious infections-related impairments may include neurological problems such as meningitis, myelitis, encephalitis and Guillain Barré syndrome [5,6]. The first and most concrete evidence on the increase in cases of microcephaly in Brazil was in 2014 and 2015 with a significant increase in 2016 where 8165 cases were reported, of which 1638 were diagnosed with microcephaly, as described in the epidemiological bulletin of Brazil [5]. In the description of probable cases of pregnant women infected with the Zika virus, 19,160 thousand cases were described mainly in the North, Midwest and Northeast regions of Brazil, this being the main suspect, responsible for microcephaly [7]. According to data, in Brazil, in 2018, 6,669 probable cases of Zika infection were registered, with two deaths reported and in the same period of $2019,9,813$ cases were counted and also two deaths. For pregnant women, 1649 cases were suspected of Zika infection with 447 confirmed cases (BRASIL,2019).

In addition to the more serious clinical manifestations, which caused a great impact as mentioned above, Zika infection has a considerable number of symptoms that are more common and may be the reason for a great difficulty in clinical diagnosis, since the most common symptoms common are infections with other arboviruses, with low fever (between 37.8 and 38.5 degrees), muscle pain (myalgia) [8,9], headache and behind the eyes plus skin rash (red spots), accompanied by itching $[9,10]$. There are also more rare symptoms of Zika virus infection include: abdominal pain, diarrhea, constipation, photophobia plus small ulcers on the oral mucosa $[11,12]$. So far there is no specific treatment or vaccine available for the infection [13], the treatment being done to control the fever and pain of those affected, in addition to the need for hydration, which proves to be similar to the treatment of Dengue cases $[14,15]$. In this way, we understand that the central objective of the management of this infection is to reduce the morbidity and mortality of the affected individuals, minimizing the viral load and the possibility of brain or other organ involvement. $[13,16]$.

Natural products for many years have been the subject of studies and are the source of most active ingredients in medicines. According [17], the first records about natural products described, it seems to have been in clay tablets in Mesopotamian cuneiform (2600 BC). These seemed to describe oils from Cupressus sempevirens (pine species) and Commiphora Cupressus sempevirens (myrrh), mainly used with anti-inflammatory action [18]. Studies point to several evidences of herbal medicines, among others, in the treatment of various diseases as described in the Ebers Papyrus (2900 BC),[19,20], which is an Egyptian pharmaceutical registry, which documents more than 700 herbal medicines ranging from gargling, pills, infusions to ointments. In this way, it is observed that the discovery of several drugs demonstrates that a high percentage (above 80\%) are of the substances of the natural products themselves or are made from natural products. There are a large number of studies with the objective of determining the mechanism of inhibition on ZIKA, and compounds derived from natural products seem to be an important strategy in this search. The studies are based on strong evidence of the inhibition of several other viruses by these products such as herpes simplex virus (HSV) [21], hepatitis B virus (HBV) [22], in addition to the Human 
Immunodeficiency Virus (HIV), allowing these studies serve as the basis for studies on ZIKA [23].

There is clear evidence of compounds with a strong potential to inhibit the replication of the ZIKA virus from products such as polyphenols, flavonoids, alkaloids, terpenes [24], among others, with different targets both in the viral structure and in the cellular mechanisms used by the virus for its replication. There is evidence of the role of Curcumin (root that comes from the ginger family plant (Zingiberaceae), native to India and used as a spice in cooking) with anti-HSV action (Herpes Simples Virus) $[25,26]$; action against Parainfluenza virus type 3 (PIV-3), vesicular stomatitis virus (VSV), herd virus (FHV) and respiratory syncytial virus (RSV) (Moghadamtousi et al., 2014). However, recent studies have shown Curcumin's strong potential against the ZIKA virus [27] with inhibitory potential on the viral envelope [28], it can be an interesting strategy to fight infection mainly in periods of outbreaks. More recently, studies by our group demonstrated the anti-Zika potential of extracts and compounds isolated from seaweed [29,30], being an important strategy in the search for compounds that can be used in therapy reducing the problem of infection[31,32].

\section{Conclusion}

Taking all these facts into account, the use of natural products, whether terrestrial or marine, can be a means of obtaining compounds with low toxicity and great efficacy in the treatment of Zika infection, especially in periods of severe outbreaks. Many of these compounds have already been shown to act on the viral particle, being a good strategy to act preventively.

\section{References}

1. Campos GS, Antonio C B, Silvia I Sardi (2015) Zika virus outbreak, Bahia, brazil. Emerging infectious diseases 21(10): 1885-1886.

2. Musso D, Roche C, Robin E, Nhan T, Teissier A, et al. (2015) Potential sexual transmission of Zika virus. Emerg Infect Dis 21(2): 359-361.

3. Miranda Filho, Celina Maria TM, Ricardo Arraes DAX, Thalia Velho B A, Maria Angela W R, et al. (2016) Initial description of the presumed congenital Zika syndrome. Am jour Public Health 106(4): 598-600.

4. Rubin E J, Michael F Greene, Lindsey R Baden (2016) Zika virus and microcephaly. N Engl J Med 374: 984-985.

5. Brasil P, Patricia Carvalho S, Andrea D Avila F, Heruza Einsfeld Z, Guilherme Amaral Calvet, et al. (2016) Guillain-Barré syndrome associated with Zika virus infection. The lancet 387(10026): 1482.

6. Dos Santos T, Angel R, Maria A, Antonio S, Pilar R, et al. (2016) Zika virus and the Guillain-Barré syndrome-case series from seven countries. New England Journal of Medicine 375(16): 1598-1601.

7. Xavier A R, Salim Kanaan, Ronielly P Bozzi, Luiza V Amaral (2017) Clinical and laboratory diagnosis of fever due to Zika virus: an update. Jornal Brasileiro de Patologia e Medicina Laboratorial 53(4): 252-257.

8. Chan J F, Arnet K Y Choi, Cyril C Y Yip, Vincent C C, Kwok Yung Yuen (2016) Zika fever and congenital Zika syndrome: an unexpected emerging arboviral disease. Joun of Infect 72(5): 507-524.
9. Falcao M B, Sergio C, Kleber G L, Alberto C, Helena A B, et al. (2016) Management of infection by the Zika virus. Annals of clinical microbiology and antimicrobials 15(1): 57.

10. De Brito (2017) Zika Virus: History and Infectology. Zika in Focus 9-32.

11. Vicente B H d S, C Nunes (2017) Zika virus: a review.

12. Papadakis M A, S J McPhee (2019) Current medical diagnosis and treatment 2019, McGraw-Hill.

13. Plourde AR, EM Bloch (2016) A literature review of Zika virus. Emerging infectious diseases 22(7): 1185-1192.

14. Loos S, H P Mallet, I Leparc G, V Gauthier, T Cardoso, et al. (2014) Current Zika virus epidemiology and recent epidemics. Med Mal Infect 44(7): 302-307.

15. Cheng F, James L M, Donald H R (2016) Drug repurposing: new treatments for zika virus infection? Trends in molecular medicine 22(11): 919-921.

16. Basarab M, Conor Bowman, Emma J A, Ian Cropley (2016) Zika virus. Bmj 352.

17. Dias D A, Sylvia Urban, Ute Roessner (2012) A historical overview of natural products in drug discovery. Metabolites 2(2): 303-336.

18. Zarshenas M M, Atefeh Arabzadeh, Mehdi Ajdari Tafti, Gholamreza Kordafshari, Arman Zargaran, et al. (2012) Application of herbal exudates in traditional Persian medicine. GMJ 1(2): 78-83.

19. Cragg G M, D J Newman (2001) Natural product drug discovery in the next millennium. Pharm bio 39(sup1): 8-17.

20. Berkov S, Blaga Mutafova, Philippe Christen (2014) Molecular biodiversity and recent analytical developments: a marriage of convenience. Biotechnology adv 32(6): 1102-1110.

21. Xiong HR, Luo J, Hou W, Xiao H, Yang ZQ (2011) The effect of emodin, an anthraquinone derivative extracted from the roots of Rheum tanguticum, against herpes simplex virus in vitro and in vivo. J Ethnopharmacol 133(2): 718-723.

22. Dang S, Xiao Li Jia, Ping Song, Yan A Cheng, Xin Zhang, et al. (2009) Inhibitory effect of emodin and Astragalus polysaccharide on the replication of HBV. World journal of gastroenterology 15(45): 56695673.

23. Batista M N, Ana Cláudia S B, Guilherme R F C, Marcos Michel S, Renata $P$ A D M et al. (2019) Natural products isolated from oriental medicinal herbs inactivate zika virus. Viruses 11(1): 49

24. Vázquez Calvo Á, Jiménez de Oya N, Martín Acebes MA, Garcia Moruno E, Saiz JC (2017) Antiviral properties of the natural polyphenols delphinidin and epigallocatechin gallate against the flaviviruses West Nile virus, Zika virus, and dengue virus. Front Microbiol 8: 1314.

25. Zandi K, Ramedani E, Mohammadi K, Tajbakhsh S, Deilami I, et al. (2010) Evaluation of antiviral activities of curcumin derivatives against HSV-1 in Vero cell line. Nat Prod Commun 5(12): 1935-1938.

26. Abubakr M, Subhash C M, Sugato B (2013) Natural compounds against flaviviral infections. Natural product communications 8(10): 1487-1492.

27. Mounce B C, Teresa C, Lucia C, Thomas V, Marco V, et al. (2017) Curcumin inhibits Zika and chikungunya virus infection by inhibiting cell binding. Antiviral research 142: 148-157.

28. Fernando S, T Fernando (2017) Antivirals for allosteric inhibition of Zika virus using a homology model and experimentally determined structure of envelope protein. BMC research notes 10(1): 354.

29. Cirne Santos C, Caroline De S B, Caio Cesar R N, Renata M C, Valéria T, et al. (2017) Inhibition of Zika virus by marine algae.

30. Cirne Santos C C, Caroline De S B, Max W L G, Rafaela G, Diana N C, et al. (2019) In Vitro Antiviral Activity Against Zika Virus from a Natural 
Product of the Brazilian Brown Seaweed Dictyota menstrualis. Natural product communications 14(7): 1934578X19859128.

31. (2016) Epidemiological Bulletin, Health Surveillance SecretariatMinistry of Health, Volume $47 \mathrm{~N}^{\circ} 38-2016$.
32. (2017) Epidemiological Bulletin, Health Surveillance SecretariatMissssnistry of Health, Volume $48 \mathrm{~N}^{\circ} 2-2017$ 